\title{
KẾT QUẢ TRIỂN KHAI GIẢNG DẠY VÀ ĐÁNH GIÁ HỌC PHẦN NHẬP MÔN NGÀNH CÔNG NGHỆ THÔNG TIN TẠI VIỆN KỸ THUẬT CÔNG NGHỆ \\ Nguyễn Thị Thủy ${ }^{(*)}$, Lê Tuấn Anh ${ }^{(* *)}$ \\ (*) Thạc sĩ. Truòng Đại học Thủ Dầu Một. Email: thuynt@tdmu.edu.vn. (**) PGS.TS. Truòng Đại học Thủ Dầu Một.Email: tuanhle@tdmu.edu.vn.
}

DOI: $10.37550 /$ tdmu.CFR/2021.01.131

\section{Tóm tắt}

Đối với các tân sinh viên (SV), việc chuyển tù môi trường phổ thông sang môi truờng đại học làm cho SV bõ ngớ, gặp nhiều khó khăn trong định hình nội dung chuoong trình đào tạo, phwơng pháp hoc tập, động lục hoc tập và định huớng nghề nghiệp tuơng lai. Nhập môn ngành là môn hoc nhà̀m đáp ứng Tiêu chuẩn 4 của CDIO về tạo cảm húng, niềm say mê, động lục học tập, khả năng sáng tạo và định hwớng nghề nghiệp trong tuoơng lai của một kỹ su kỹ thuật [1]. Mặt khác, môn học bước đầu rèn luyện cho SV tu duy thực hành kỹ thuật qua việc kiến tạo sản phẩm, quy trình, và hệ thống. Bài viết này, chia sẻ nhũng kết quả đạt được qua quá trình triển khai giảng dạy Nhập môn ngành Công nghệ thông tin (CNTT) tại trương Viện Kỹ thuật Công nghệ, đồng thời nêu ra một số thách thức trong quá trình triển khai.

Tù̀ khóa: Nhập môn ngành CNTT; Tiêu chuẩn 4 CDIO; Kiến tạo sản phẩm, quy trình

\section{1. Đặt vấn đề}

Mục tiêu và nhiệm vụ của giáo dục đại học là đào tạo nhân lực đáp ứng nhu cầu phát triển của xã hội và quan trọng hơn là làm sao để $S V$ có được các kiến thức, kỹ năng và thái độ mà doanh nghiệp và các bên liên quan mong muốn. Đề xướng $\mathrm{CDIO}$ đáp ứng thách thức này thông qua việc đào tạo $\mathrm{SV}$ trở thành người kỹ sư toàn diện, hiểu được cách thức Hinh thành ý tuởng - Thiết kế - Triển khai - Vận hành những sản phẩm, quy trình và những hệ thống kỹ thuật phức tạp, có giá trị gia tăng, trong môi trường hiện đại, làm việc theo nhóm [2]. Tuy vậy, việc thay đổi môi trường học tập từ phổ thông sang đại học sẽ ít nhiều làm cho các tân SV gặp nhiều bỡ ngỡ, khó khăn. Chẳng hạn, họ chưa định hình được nội dung chương trình, phương pháp học tập và nghề nghiệp tương lai của mình, từ đó dẫn đến $S V$ thiếu động cơ học tập, thiếu một số kỹ năng cần thiết. Vì vậy, SV gặp khó khăn trong học tập ở các năm tiếp theo.

Môn học "Nhập môn về kỹ thuật" là Tiêu chuẩn 4 trong số 12 tiêu chuẩn của CDIO. Tiêu chuẩn này khẳng định đây là môn học giới thiệu khuôn khổ thực hành kỹ thuật cho 
việc chế tạo sản phẩm, thiết lập quy trình và xây dựng hệ thống; giới thiệu các kỹ năng cá nhân và giao tiếp cần thiết [6]. Nhập môn ngành kỹ thuật đã được triển khai ở nhiều CTĐT trong và ngoài nước. Chẳng hạn, ứng dụng khái niệm Constructive Alignment để xây dựng môn giới thiệu ngành được đề cập trong [3], tác giả đã nêu vai trò và tầm quan trọng của môn giới thiệu ngành và ví nó như một bộ phận trung tâm trong CTĐT tích hợp. Một mô hình tổ chức Nhập môn CNTT với hai môn Nhập môn CNTT 1 và Nhập môn CNTT 2 được triển khai để đáp ứng nhu cầu giới thiệu cho SV 6 chuyên ngành tại Khoa CNTT, trường ĐH Khoa học Tự nhiên TP.Hồ Chí Minh [4].

Hiện nay, Nhập môn ngành là môn học bắt buộc đối với SV tất cả các ngành của trường $\mathrm{ĐH}$ Thủ Dầu Một. Nhập môn ngành CNTT được chúng tôi đề cập trong bài viết này ngoài việc đáp ứng mục tiêu của Tiêu chuẩn 4 , còn được vận dụng linh hoạt phù hợp với điều kiện của Trường và các chuyên ngành đào tạo của Viện Kỹ thuật Công nghệ. Nội dung Nhập môn ngành của Viện Kỹ thuật Công nghệ có một số phần tương tự như Nhập môn CNTT 1 và Nhập môn CNTT 2 của trường ĐH Khoa học Tự nhiên TP. Hồ Chí Minh, tuy nhiên, từ quy trình kiến tạo sản phẩm, quy trình chúng tôi tăng cường nội dung trải nghiệm và thực hành phát triển sản phẩm CNTT thông qua đồ án môn học cuối kỳ.

Phần tiếp theo của bài viết này được tổ chức như sau. Trong Phần II, trình bày cấu trúc nội dung, phương pháp dạy học và đánh giá của môn Nhập môn ngành đang triển khai. Phần III giới thiệu các kết quả đạt được của quá trình triển khai CDIO tại Viện, và Phần IV nêu một số thách thức khi triển khai Nhập môn ngành. Cuối cùng là kết luận.

\section{Cấu trúc nội dung, phương pháp dạy - học và đánh giá}

\subsection{Cấu trúc nội dung môn học}

Nội dung của môn học Nhập môn ngành CNTT được thiết kế với thời lượng 3 tín chỉ (gồm 30 tiết lý thuyết và 30 tiết thực hành) được trình bày trong Hình 1 .

Trong Hình 1, kiến thức liên quan đến CNTT và các lĩnh vực ứng dụng CNTT trong xã hội sẽ được trình bày qua phần Giới thiệu ngành nghề và các lĩnh vưc ứng dụng. Phần Kỹ năng khai thác thông tin và giao tiếp bằng điện tử sẽ giảng dạy một số kỹ năng về tìm kiếm, khai thác, xử lý và giao tiếp trên Internet. Các kỹ năng cá nhân như làm việc nhóm, kỹ năng thuyết trình, kỹ năng giải quyết vấn đề sẽ được giới thiệu trong phần $K \tilde{y}$ năng cá nhân. Các kiến thức về đạo đức, cách hành xử có đạo đức liên quan đến ngành nghề và một số ví dụ về đạo đức trong CNTT chúng tôi sẽ chọn lọc và trình bày trong phần Giới thiệu đạo đức nghề nghiệp của kỹ su CNTT. Đặc biệt, với mục tiêu giúp SV hiểu được cách thức Hình thành ý tưởng - Thiết kế - Thực hiện - Vận hành một sản phẩm, một quy trình thực tế, chúng tôi cho SV trải nghiệm qua các bước Kiến tạo sản phẩm. Phần cuối của môn học sẽ giúp sẽ bước đầu làm quen với cách xây dựng, cách viết báo cáo và trình bày một đồ án qua nội dung Phát triển ứng dụng CNTT.

Ngoài các nội dung trên, nhằm giúp các tân $\mathrm{SV}$ có cảm hứng học tập, rút ngắn khoảng cách giữa môi trường học tập và công việc thực tế, hàng năm Viện đã mời các chuyên gia, doanh nghiệp seminar các chương trình định hướng nghề nghiệp dành cho SV năm nhất như Hình 2; kết hợp với các công ty phần mềm tổ chức cho $\mathrm{SV}$ tham quan tìm hiểu môi trường 
làm việc, vị trí việc làm tại doanh nghiệp để giúp SV hiểu rõ hơn về nghề nghiệp tương lai và các yêu cầu về kiến thức nền tảng, công nghệ và các kỹ năng cần thiết của một người kỹ sư (Hình 3). Qua các buổi trao đổi kinh nghiệm thực tế này sẽ tạo động lực cho SV phấn đấu, theo đuổi đam mê và có định hướng cho công việc tương lai của mình.

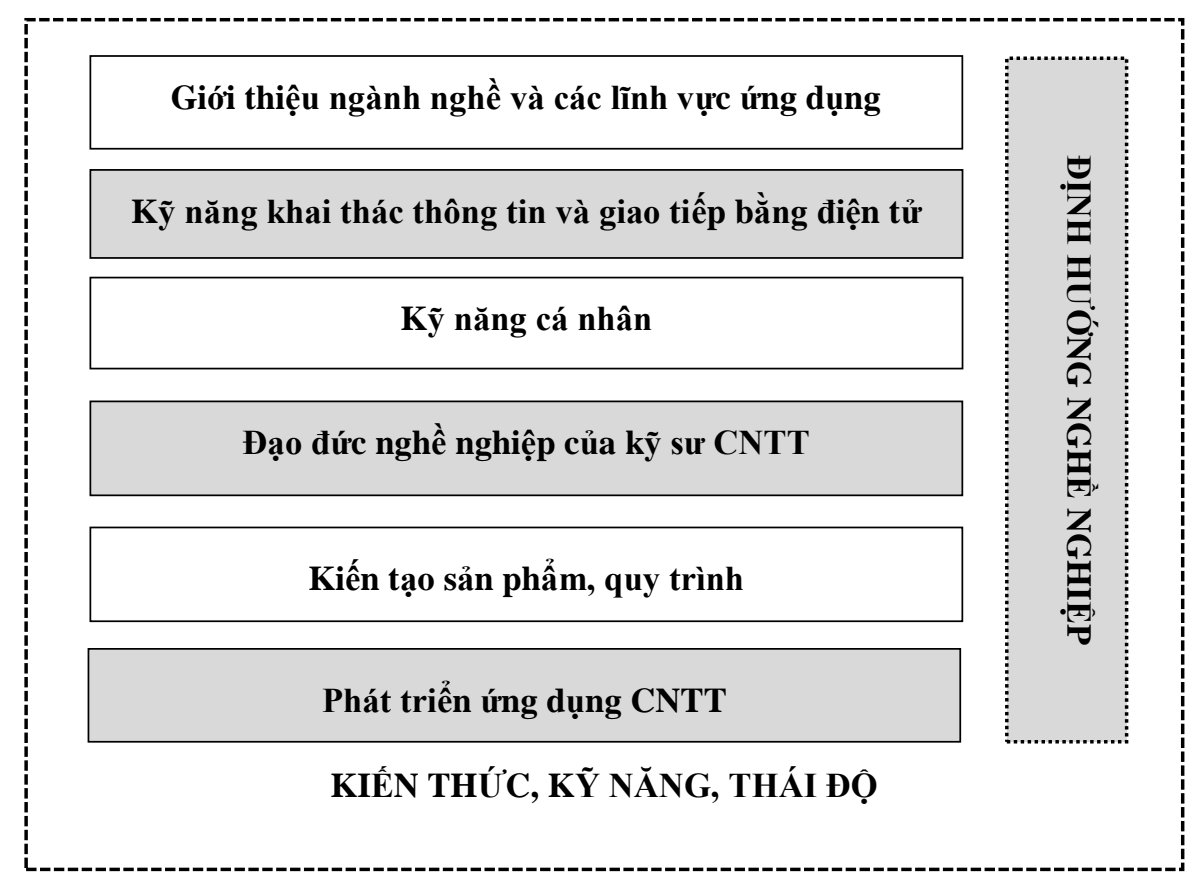

Hinh 1. Nội dung môn học Nhập môn ngành CNTT

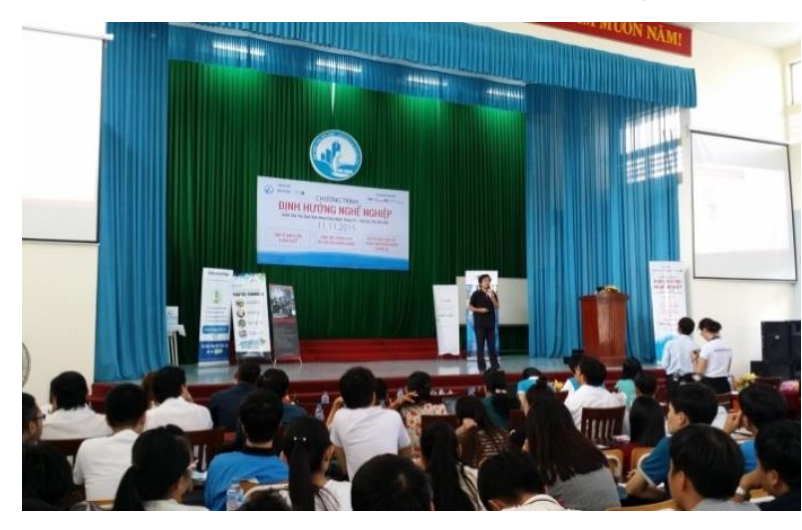

Hinh 2. Chuơng trình định hướng nghề nghiệp cho tân $S V$

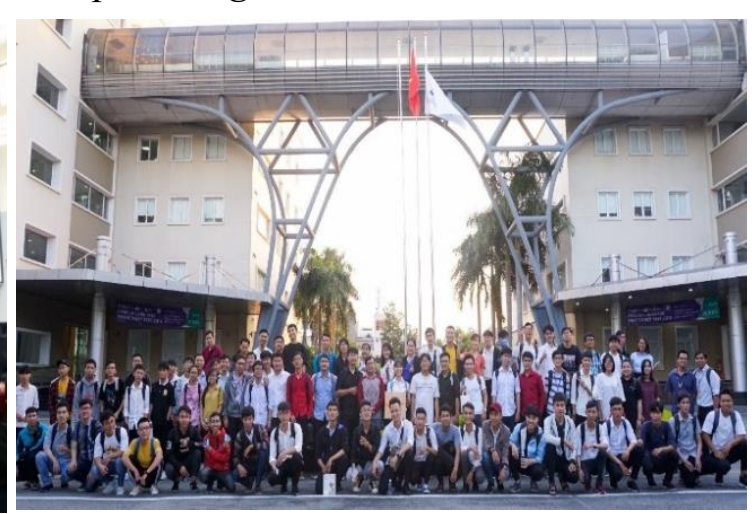

Hình 3. SV tham quan thục tế tại FPT software

\subsection{Phương pháp dạy và học}

Mục tiêu của Nhập môn ngành là tạo cảm hứng, niềm say mê, động lực học tập, khả năng sáng tạo và định hướng nghề nghiệp trong tương lai của một kỹ sư kỹ thuật, do vậy môn học này không đặt nặng về kiến thức mà chủ yếu chú trọng phát triển năng lực cho SV, đặc biệt là những năng lực cốt lõi cho sự phát triển bản thân, phát triển nghề nghiệp và 
giao tiếp xã hội để SV thực sự gắn kết và bắt kịp với sự phát triển của ngành nghề sau này. Do vậy đòi hỏi giảng viên $(\mathrm{GV})$ có phương pháp giảng dạy thích hợp và SV phải thay đồi cách học để đáp ứng được yêu cầu của môn học.

Đối với môn học này, SV sẽ học các kỹ năng cá nhân, kỹ năng giao tiếp, các kỹ năng kiến tạo sản phẩm cùng với kiến thức chuyên ngành CNTT. Cách học này cho phép SV sử dụng kép thời gian để vừa học kiến thức, vừa học kỹ năng. Với hình thức học tập thông qua trải nghiệm sớm các đồ án; cho SV làm mini project; tranh luận các câu hỏi có vấn đề... sẽ giúp $\mathrm{SV}$ tự tin trao đổi, thảo luận, phân tích và đánh giá các ý tưởng của mình/bạn cùng nhóm như Hình 4. Sau đây là một số ví dụ về cách tổ chức giảng dạy và học tập được chúng tôi thực hiện trong môn học này.

Trong nội dung Đạo đức nghề nghiệp của người kỹ su CNTT, để giúp SV tự chiếm lĩnh tri thức và có thái độ đúng đắn với đạo đức nghề nghiệp ngành $\mathrm{CNTT}, \mathrm{GV}$ sử dụng phương pháp dạy học theo mô hình CARD (Context Activity Reflect Documentation) [5]. Sau khi giới thiệu nội dung bài học, $\mathrm{GV}$ cho $\mathrm{SV}$ xem một clip về đạo đức nghề nghiệp, sau khi xem xong clip GV đặt các câu hỏi thảo luận, cuối cùng từng SV suy ngẫm và viết ra những việc nên/ không nên làm của một kỹ sư CNTT. Bài tập cho nội dung này, các nhóm xây dựng một clip về đạo đức CNTT, tội phạm CNTT trong xã hội và chia sẻ cho cả lớp cùng theo dõi.

Một ví dụ khác, GV sẽ cho SV trải nghiệm quy trình CDIO dựa trên đồ án thông qua các bước trong nội dung Kiến tạo sản phẩm. Cụ thể, chúng tôi đã cho các nhóm SV trải nghiệm quy trình Lên ý tưởng - Thiết kế - Xây dựng và Thử nghiệm sản phẩm qua bài tập xây dựng một hình tháp từ các nguyên liệu cho trước, với yêu cầu tháp có thể đứng vững trên mặt phẳng nghiêng $45^{\circ}$ và chịu được một vật nặng được gắn trên đỉnh tháp. Các nhóm tự lập bảng thiết kế, bảng chấm công, quy trình thực hiện, nêu khó khăn và giải pháp thực hiện, sau đó viết báo cáo trình bày sản phẩm trước lớp như Hình 5 . Hoạt động này đã lôi cuốn SV tham gia nhiệt tình, không khí học tập sôi nổi, bổ ích và xác thực. Sau khi SV đã biết được một quy trình kiến tạo sản phẩm, chúng tôi yêu cầu SV tự khảo sát một bài toán trong thực tế để xây dựng một đồ án môn học. Yêu cầu của đồ án, xây dựng một bài toán nhỏ giải quyết một vấn đề trong thực tế. Ví dụ: xây dựng một bài toán quản lý, thiết kế một Website, thực hiện game,... từ các công cụ hoặc mã nguồn có sẵn. Mặc dù với lượng kiến thức về chuyên ngành còn hạn chế tuy nhiên đồ án đã được $\mathrm{SV}$ thực hiện rất tốt. Như vậy, thay vì chỉ đơn thuần dạy lý thuyết trừu tượng, hay cho $\mathrm{SV}$ thực hành, làm bài tập ở nhà thì việc cho $\mathrm{SV}$ tham gia sớm vào đồ án sẽ bước đầu cho họ cơ hội khám phá và thực hiện những điều họ mong muốn làm khi vào trường đại học.
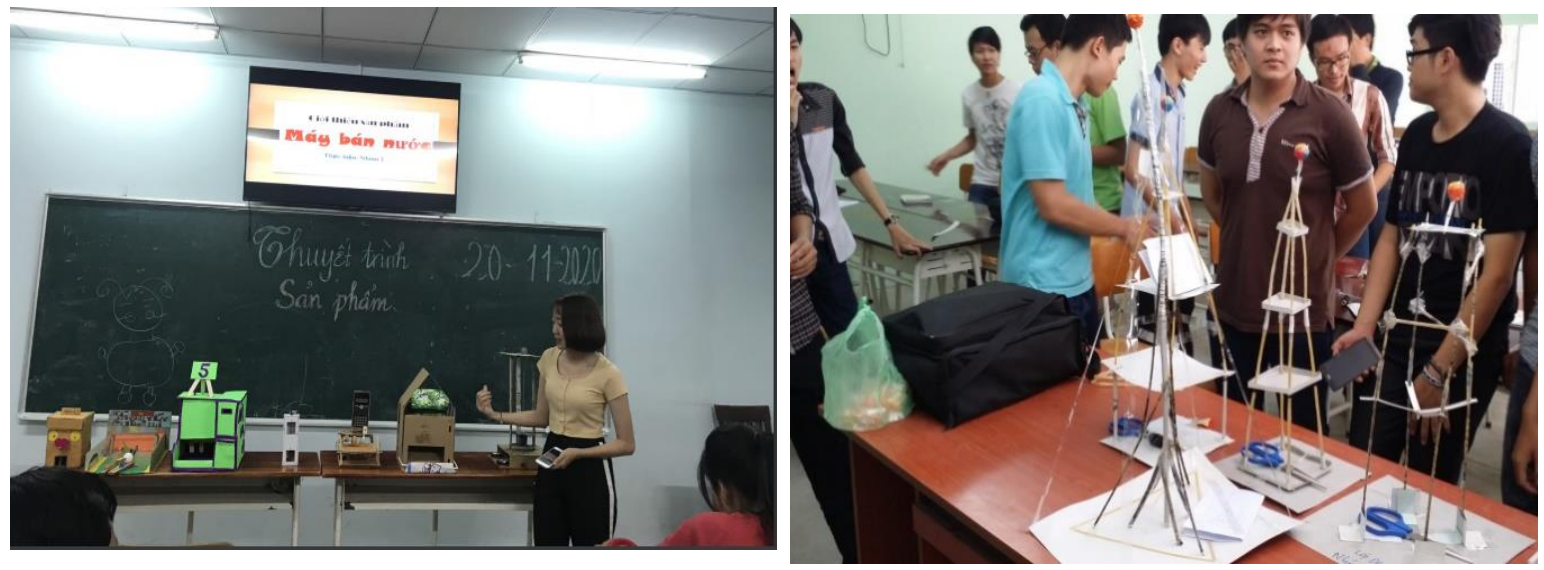
Hinh 4. SV rèn luyện kỹ năng làm việc nhóm và thuyết trìn.
Hình 5. Sản phẩm SV trải nghiệm qua các buơóc kiến tạo sản phẩm.

\section{3. Đánh giá kết quả học tập}

Nhằm đạt được mục tiêu đề ra ở trên, trong môn học này chúng tôi thiết kế các dạng bài tập đánh giá như sau:

- Đánh giá hoạt động trên lớp (10\%): Bao gồm các hoạt động Tham dự đầy đủ các buổi học; Tích cực trả lời các câu hỏi, trao đổi, thảo luận; Làm bài tập.

- Bài tập cá nhân/tuần (10\%): Ở dạng này nhiệm vụ của SV chuẩn bị nội dung cho bài giảng ở tuần tiếp theo bằng cách đọc và tóm tắt bài giảng trên lớp, chuẩn bị bài tập, bài thực hành, các câu hỏi thảo luận...Qua đó, kiểm tra kỹ năng đọc, viết, phân tích, tổng hợp, tư duy phản biện của $S V$...

- Bài tập theo nhóm/tháng (30\%): Mỗi nhóm từ 2-3 SV có nhiệm vụ tự tìm hiểu và xây dựng một mini project theo yêu cầu của $G V$. Với dạng bài tập này, nhằm kiểm tra kiến thức, kỹ năng tự học, tự nghiên cứu của $\mathrm{SV}$, qua đó rèn luyện các kỹ năng làm việc nhóm, kỹ năng quản lý, sử dụng thời gian, giải quyết vấn đề... bên cạnh đó, các kỹ năng nghe, nói, đọc, viết cũng được củng cố.

- Bài kiểm tra cuối kỳ (50\%): Nhằm đánh giá toàn diện về kiến thức, kỹ năng và thái độ của $\mathrm{SV}$, bài cuối kỳ tổ chức viết báo cáo: Vận dụng các công cụ đã được học đề xuất giải quyết một vấn đề cụ thể từ khảo sát thực tế (20\%); Thuyết trình vấn đề nhóm đã làm $(10 \%)$. Trình bày báo cáo bằng văn bản $(10 \%)$. Cuối cùng viết một đoạn ngắn nêu cảm nhận của bản thân về ngành học $(10 \%)$.

\section{Kết quả thực hiện}

Quá trình khiển khai Nhập môn ngành CNTT tại Viện bước đầu đã mang lại một số kết quả khả quan. Môn học này không những tác động tích cực đến $\mathrm{SV}$ mà còn giúp $\mathrm{GV}$ thay đổi phương pháp giảng dạy và giúp Viện định hướng nâng cao năng lực và kỹ năng giảng dạy cho GV, phối hợp trải nghiệm bên ngoài Trường.

Để đánh giá tác động môn học này đối với $\mathrm{SV}$, sau khi kết thúc học kỳ chúng tôi tiến hành khảo sát để lấy ý kiến của $\mathrm{SV}$ về sự yêu thích môn học này. Kết quả khảo sát được thực hiện trong 5 năm liên tục từ 2015 đến 2019. Phiếu khảo sát gồm có 30 câu thuộc 5 lĩnh vực: Thông tin chung về môn học; Hoạt động giảng dạy của GV; Sự kết hợp giữa lý thuyết và thực hành của môn học; Kiểm tra đánh giá; và Cảm nhận chung về môn học. Ở đây, chúng tôi chỉ trích lọc một số kết quả liên quan đến kiến thức, kỹ năng, thái độ của SV đối với môn học này. Biểu đồ 1 thể hiện các kết quả về kiến thức và kỹ năng, cụ thể như sau:

Về kiến thức: Kết quả khảo sát cho thấy có $36 \% \mathrm{SV}$ hoàn toàn đồng ý, $60 \% \mathrm{SV}$ đồng ý khi nhận xét rằng môn học này cung cấp cho họ những kiến thức bổ ích. Hơn $50 \% \mathrm{SV}$ đồng ý rằng môn học này đã giúp họ nâng cao năng lực tư duy nhận thức và rèn luyện tư duy giải quyết vấn đề. 
Về kñ năng: Đa số SV có phản hồi tích cực đối với các kỹ năng đã đạt được trong môn học này. Cụ thể, có $46 \%$ hoàn toàn đồng ý và $52 \%$ đồng ý với nhận xét Nhập môn ngành giúp họ phát triển một số kỹ năng cá nhân cần thiết: tự học, giao tiếp, thuyết trình, làm việc nhóm; kỹ năng khai thác thông tin trên Internet; kỹ năng học tập tích hợp; kỹ năng tư duy phản biện.
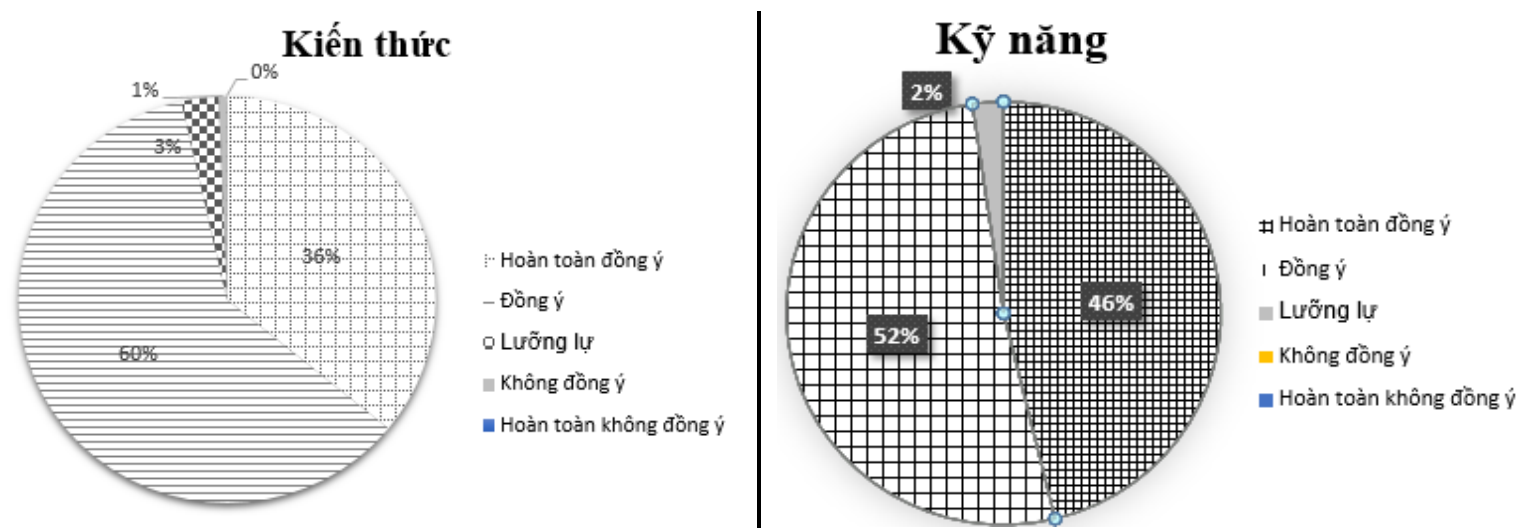

Biểu đồ 1. Ý kiến phản hồi của SV về kiến thức và kỹ năng qua môn học Nhập môn ngành CNTT.

Về thái độ: Có $81 \% \mathrm{SV}$ nhận thức được tầm quan trọng của môn học này trong chương trình đào tạo, $56 \%$ cho rằng môn học giúp họ có định hướng nghề nghiệp cho bản thân, $78 \% \mathrm{SV}$ yêu thích môn học, $79 \% \mathrm{SV}$ có thái độ đúng đắn với những sai phạm liên quan đến đạo đức CNTT trong xã hội.

Bên cạnh đó Nhập môn ngành đã có ảnh hưởng lớn đến kết quả học tập của một số môn chuyên ngành như "Cơ sở Lập trình", "Kỹ Thuật lập trình", hay "Thiết kế Website". So với kết quả của các khóa trước năm 2015 thì kết quả học tập các môn này của các năm 2015 đến 2019 cao hơn [7].

Ngoài những tác động tích cực đến SV, Nhập môn ngành CNTT đã giúp GV hiểu được ngữ cảnh $\mathrm{CDIO}$ trong giảng dạy kỹ thuật, từ đó vận dụng vào quá trình thiết kế đề cương môn học theo $\mathrm{CDIO}$ nhằm đáp ứng các tiêu chuẩn của $\mathrm{AUN}$, MOET; lồng ghép các kỹ năng để giải quyết các vấn đề thực tế cho $\mathrm{SV}$ trong từng bài giảng, đặc biệt rèn luyện kỹ năng CDIO cho SV qua các bài thực hành, đồ án môn học. [5]

\section{Thách thức}

Bên cạnh những thuận lợi nhất định, việc triển khai giảng dạy Nhập môn ngành theo đề xướng CDIO đã gặp một số khó khăn và thách thức:

- Thách thức lớn nhất trong môn học này là thời lượng còn ít, không đủ để triển kahi các hoạt động trải nghiệm thực tiễn cho SV;

- Kinh nghiệm giảng dạy theo CDIO giữa các GV chưa đều;

- Cách thức đánh giá rất chi tiết đòi hỏi GV phải mất nhiều thời gian và công sức,

- SV phải chủ động học tập và rèn luyện mới có thể đáp ứng tốt yêu cầu của môn học; 
- Một số phương pháp học tập hiệu quả [6] chưa được giới thiệu nhiều cho SV.

\section{Kết luận}

Việc triển khai giảng dạy Nhập môn ngành cho SV từ năm đầu tiên của bậc đại học là một hướng đi đúng đắn của Nhà trường và bước đầu đã thu được một số kết quả khả quan. Môn học này đã giúp SV nhìn nhận tổng quan được quá trình học tập của mình trong 4 năm học, hiểu rõ hơn về nghề nghiệp mà mình đã chọn, từ đó các em sẽ có phương pháp học tập và lộ trình phát triển nghề nghiệp. Trải nghiệm giảng dạy môn học đã giúp Viện và $G V$ có những cải tiến để phù hợp với mục tiêu đào tạo. Tuy vậy, việc triển khai Nhập môn ngành đã gặp một số thách thức nhất định. Chúng tôi sẽ từng bước khắc phục những khó khăn để đạt được mục tiêu đề ra.

\section{Tài liệu tham khảo}

[1] 12 Tiêu chuẩn của CDIO, http://www.cdio.org, truy cập ngày 03/11/2020.

[2] E. Crawley, J. Malmqvist, S. Ostlund, D. Brodeur, "Rethinking Engineering Education: The CDIO Approach", Springer, 2007. Bản dịch tiếng Việt: Hồ Tấn Nhựt, Đoàn Thị Minh Trinh, "Cải cách và xây dựng CTĐT kỹ thuật theo phương pháp tiếp cận CDIO", NXB ĐHQG- HCM, 2010.

[3] Hồ Tấn Nhựt, "Thiết kế - Triển khai môn học giới thiệu về ngành kỹ thuật", Hội nghị CDIO toàn quốc 2012, p161-174, 2012.

[4] Trần Thái Sơn, Huỳnh Thụy Bảo Trân, Trần Trung Dũng, Phạm Nguyên Cương, Đặng Bình Phương, Nguyễn Đình Thúc, Cao Đăng Tân, Đồng Thị Bích Thủy, Lê Hoài Bắc, "Nhập môn Công nghệ Thông Tin”, Hội nghị CDIO toàn quốc 2012, p118-127, 2012.

[5] Andrew, "Instruction Skills Workshop", Bản dịch tiếng Việt: "Chuoong trình về các kỹ năng giảng day", 2015.

[6] Phạm Ngọc Tuấn, Hồ thị Thu Nga, Đỗ Thị Ngọc Khánh, Trần Đại Nguyên, Nguyễn văn Tường, Nguyễn Minh Hà, "Nhập môn về kỹ thuật", NXB ĐHQG TP. Hồ Chí Minh, 2015.

[7] Kết quả học tập của SV nhóm ngành CNTT từ khóa 2015 đến Khóa 2019. 